\title{
Infecções em cateteres venosos centrais de longa permanência: revisão da literatura
}

\author{
Infection of long-term central venous catheters: review of the literature
}

\author{
Milton Alves das Neves Junior, Rafael Couto Melo, Adenauer Marinho de Oliveira Goes Junior, \\ Tatiana Rocha Protta, Catarina Coelho de Almeida, Allison Roxo Fernandes, Alexandre Petnys, \\ Edgar Raboni*
}

\section{Resumo}

Cateteres venosos de longa permanência são amplamente utilizados em pacientes com necessidade de acesso venoso por período prolongado. A infecção relacionada a esses cateteres permanece um desafio na prática clínica. Revisamos a literatura acerca da epidemiologia e tratamento das infecções relacionadas a cateteres. Staphylococcus aureus é a bactéria mais comumente isolada. Os cateteres semi-implantáveis apresentam taxas de infecção maiores que os totalmente implantáveis. O tratamento pode ser feito com locks, antibioticoterapia sistêmica e até mesmo com retirada do cateter, dependendo do tipo de infecção, do microrganismo isolado e das condições clínicas do paciente. O salvamento do cateter deve ser tentado sempre que possível.

Palavras-chave: Cateteres de demora, diálise renal, quimioterapia.

\section{Introdução}

Os cateteres venosos centrais de longa permanência são utilizados em situações em que há necessidade de acesso prolongado ou definitivo ao sistema vascular, encontrando uso clínico frequente em hemodiálise, hemoterapia, quimioterapia e nutrição parenteral prolongada (NPP). São manufaturados em silicone ou poliuretano, constituídos de lúmen único ou múltiplo, podendo ser semi ou totalmente implantáveis ${ }^{1}$.

Apresentam complicações diversas relacionadas ao seu implante, à manipulação e à manutenção. A infecção em cateteres de longa permanência constitui complicação de grande morbimortalidade, com riscos e agravos adicionais em pacientes muitas vezes debilitados ou imunossuprimidos, como aqueles submetidos à quimioterapia. Em pacientes em hemodiálise, a referida infecção é causa frequente de reinternações e compõe a segunda causa de morte em tais pacientes ${ }^{2}$. Justifica-se, dessa forma, um progra-

\begin{abstract}
Long-term venous catheters are widely used in patients with needs of venous access for prolonged periods. The infection related to these catheters remains a challenge in clinical practice. We reviewed the literature about infection epidemiology and treatment related to catheters. Staphylococcus aureus is the most common isolated bacteria. Tunneled catheters present higher infection rates than implanted ports. Treatment may consist in the use of locks, systemic antibiotics, and even catheter removal, depending on the kind of infection, the isolated microorganism, and the patient's clinical conditions. Catheter salvation should be tried whenever possible.
\end{abstract}

Keywords: Indwelling catheters, renal dialysis, drug therapy.

ma de vigilância e abordagem agressiva em pacientes portadores desses cateteres com suspeita diagnóstica ou em vigência de infecção. Há controvérsias quanto à melhor forma de tratamento, devendo-se levar em conta o tipo de infecção, o microrganismo responsável, as condições clínicas do paciente, a necessidade do acesso venoso e o tipo de cateter envolvido. Nos casos de cateteres de longa permanência são válidas tentativas de salvamento dos cateteres quando possível, evitando-se múltiplas punções e esgotamento dos acessos em pacientes com histórico frequente de acesso venoso difícil.

Este artigo de revisão da literatura tem com objetivo traçar um protocolo de reconhecimento, tratamento e prevenção da infecção de cateteres venosos de longa permanência. Foram revisados artigos presente nas bases de dados PubMed e BIREME relacionados à infecção nesse tipo de cateteres, sejam eles para hemodiálise, quimioterapia ou NPP, bem como capítulos de livros-texto e diretri-

\footnotetext{
Não foram declarados conflitos de interesse associados à publicação deste artigo.

Artigo submetido em 25.04.09, aceito em 16.12.09.

J Vasc Bras. 2010;9(1):46-50.

Copyright @ 2010 by Sociedade Brasileira de Angiologia e de Cirurgia Vascular
}

*Cirurgiões vasculares, Serviço de Cirurgia Vascular, Hospital do Servidor Público Municipal de São Paulo (HSPM), São Paulo, SP. 
zes sobre o assunto. Foram levantados os seguintes dados: índice de infecção, microrganismo isolado, formas de tratamento, taxas de sucesso.

\section{Epidemiologia}

A infecção é a complicação mais grave associada aos cateteres. De uma forma geral, ela ocorre em aproximadamente $19 \%$ dos pacientes em uso desse dispositivo, sendo $7 \%$ infecções locais e $12 \%$ casos de bacteremia associada ao cateter ${ }^{3}$.

Os cateteres semi-implantáveis de longa permanência possuem um trajeto subcutâneo associado a um cuff de dácron capaz de criar fibrose pericateter reduzindo a chance de infecção em relação aos cateteres de curta permanência, como o duplo lúmen. Os totalmente implantáveis, por não possuírem nenhuma parte exteriorizada, têm índice ainda menores de contaminação.

Nos cateteres semi-implantáveis de longa permanência utilizados em hemodiálise, a infecção é a complicação tardia mais frequente ${ }^{4}$, sendo o Staphylococcus aureus o agente mais isolado ${ }^{4,5}$, seguido por bacilos gram-negativos e pelo Staphylococcus coagulase negativo ${ }^{6}$.

Os cateteres de Broviac (semi-implantável de lúmen único) e de Hickman (semi-implantável de duplo lúmen) são bastante utilizados em pacientes com NPP. Marcondes et al. ${ }^{4}$ relatam que esses cateteres têm os maiores índices de infecção.

Os cateteres totalmente implantáveis (port-o-cath), utilizados para quimioterapia, por não terem nenhuma parte exposta, apresentam índices de infecção menores. Groeger et al. ${ }^{7}$ mostram infecção de $43 \%$ dos cateteres semi-implantáveis contra $8 \%$ dos totalmente implantáveis em pacientes com câncer. Para D'Angelo et al. ${ }^{8}$, a bacteremia relacionada ao cateter ocorreu em $4,34 \%$ dos cateteres totalmente implantáveis. O Staphylococcus aureus é a bactéria mais prevalente ( $50 \%$ dos casos). Biffi et al. ${ }^{9}$ relatam apenas $0,3 \%$ de infecção da loja do porto e $2,4 \%$ de bacteremia relacionada ao cateter.

\section{Diagnóstico}

Caracterizar o tipo de infecção do cateter é o primeiro passo para a correta conduta terapêutica. As infecções são divididas em: 1) infecção do óstio, 2) infecção do túnel ou da bolsa e 3 ) bacteremia relacionada ao cateter ${ }^{10-12}$.
A infecção do óstio se caracteriza pela hiperemia e/ou saída de secreção purulenta que se estende até $2 \mathrm{~cm}$ do orifício por onde se exterioriza o cateter.

A infecção do túnel do cateter apresenta hiperemia e/ou saída de secreção por mais de $2 \mathrm{~cm}$ do orifício do cateter; nos cateteres totalmente implantáveis, a hiperemia da loja do porto caracteriza a infecção da loja.

A bacteremia relacionada ao cateter é a presença de febre e/ou calafrios em pacientes com cateter venoso central sem outro foco infeccioso aparente. Nesses casos, o paciente deve ser investigado com a coleta de hemoculturas tanto periférica como do próprio cateter. Algumas maneiras de interpretação dos resultados dessas coletas são sugeridas na literatura, auxiliando na confirmação diagnóstica. São elas: a) técnica semiquantitativa de Maki, que é positiva quando há mais de 15 unidades formadora de colônias (UFC) por placa; b) crescimento de 5 a 10 vezes UFC/mL de sangue nas amostras colhidas pelo cateter e periférica; c) crescimento de $1.000 \mathrm{UFC} / \mathrm{mL}$ de sangue colhido pelo cateter ${ }^{10,13-15}$.

\section{Tratamento}

O tratamento das infecções relacionadas a cateteres depende do tipo de microrganismo presente, do tipo de cateter, dos sintomas sistêmicos e do tipo de infecção.

A infecção do óstio apresenta menor gravidade e responde bem a cuidados locais com curativo e tratamento tópico, não sendo necessária a retirada do cateter ${ }^{10,11}$.

A infecção do túnel ou da bolsa não responde bem à antibioticoterapia sistêmica isolada, sendo necessária a retirada do cateter ${ }^{10,11}$.

O tratamento da bacteremia relacionada ao cateter pode ser feito com locks, antibioticoterapia e remoção do cateter $^{13}$. Por se tratar de acessos de longa permanência, deve-se tentar o "salvamento" desses cateteres, porém sem colocar em risco a saúde dos pacientes. A indicação e o momento de retirada permanecem controversos na literatura.

Poole et al. ${ }^{16}$ relatam que, em cateteres de hemodiálise, o sucesso do tratamento dos pacientes com bacteremia relacionada ao cateter com locks de vancomicina ou ceftazidima associada a heparina depende do microrganismo em crescimento na cultura, atingindo índices de sucesso de $87 \%$ para bactérias gram-negativas, $75 \%$ para Staphylo- 
coccus coagulase negativo e apenas $40 \%$ para Staphylococcus aureus. Para Maya et al. ${ }^{17}$, o uso de antibióticos sistêmicos e em locks foram capazes de salvar os cateteres infectados por Staphylococcus aureus em apenas $41 \%$ dos casos. Para Lentino et al. ${ }^{6}, 89 \%$ dos acessos vasculares em pacientes com infecção foram removidos, porém sem melhora na mortalidade desses pacientes. Dugdale \& Ramsey ${ }^{18}$ recomendam a retirada precoce dos cateteres infectados por Staphylococcus aureus a menos que exista outro possível foco para infecção ou que a cultura quantitativa mostre menos que $1 \mathrm{UFC} / \mathrm{mL}$. Raad \& Sabbagh ${ }^{19}$ relatam que pacientes com bacteremia relacionada ao cateter por Staphylococcus aureus devem ser tratados com remoção do cateter e antibioticoterapia endovenosa por 10-14 dias e que a manutenção da febre ou cultura positiva após 3 dias do início do tratamento podem indicar complicações como endocardite ou osteomielite. Independentemente do microrganismo isolado, caso o paciente apresente bacteremia complicada (febre/calafrios associados à hipotensão ou cianose), está indicada a retirada do cateter ${ }^{10}$.

As infecções fúngicas são encontradas em 10-30\% das culturas $^{10}$. Candida é o fungo mais comumente isolado ${ }^{10}$, mas Rhodotorula spp ${ }^{20}$ e Malassezia spp também podem ser encontrados ${ }^{21,22}$, geralmente em pacientes debilitados. Agarwal et al. ${ }^{23}$ recomendam a retirada do cateter associado ao uso de anfotericina B via endovenosa. Entretanto, alguns autores têm mostrado sucesso no salvamento do cateter utilizando lock com anfotericina B para infecções não complicadas ${ }^{24,25}$.

\section{Prevenção e cuidados com o cateter}

Os cuidados para a prevenção da infecção dos cateteres venosos de longa permanência se iniciam no momento de sua implantação. Todo o procedimento deve ser realizado em centro cirúrgico, e toda a equipe deve estar paramentada. O paciente deve ser preparado com tricotomia prévia, se necessário. Na sala operatória, a assepsia do

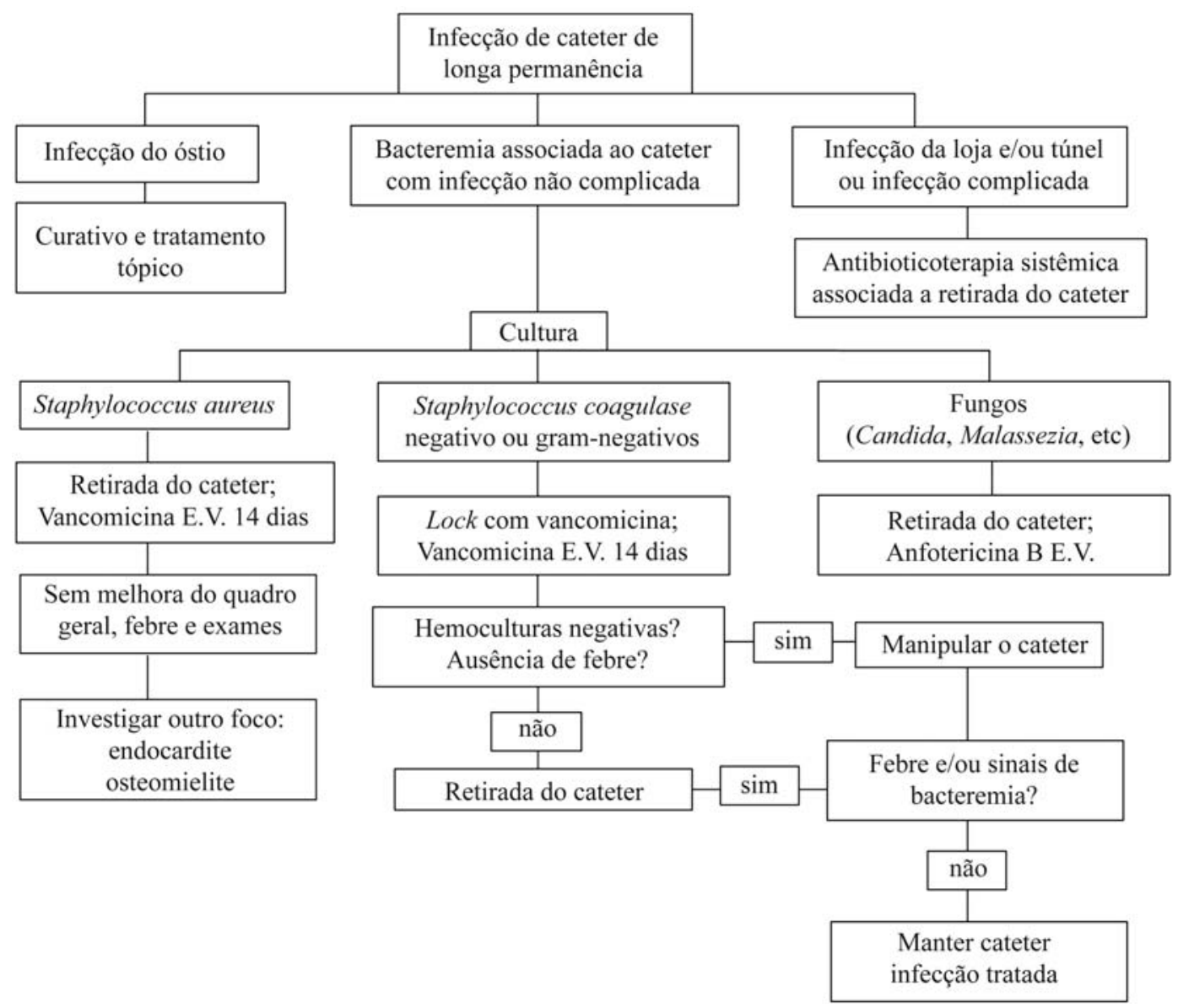

Figura 1 - Algoritmo de tratamento dos pacientes com infecção de cateter venoso central de longa permanência 
local de implantação é feita mediante uso de solução degermante seguido por aplicação de solução alcoólica. O paciente é, então, coberto com campos estéreis.

Cada manipulação deve ser precedida de antissepsia adequada. Após a manipulação, o cateter deve receber solução de heparina exatamente no volume indicado no cateter. Isso previne a formação de trombos no lúmen e pericateter, reduzindo a possibilidade de fixação bacteriana e posterior infecção. Existem no mercado soluções bacteriostáticas que podem substituir a heparina. Ambas as soluções devem ser aspiradas antes da nova utilização do cateter.

Os cateteres semi-implantáveis requerem curativos no seu segmento exposto após cada utilização. Já os totalmente implantáveis necessitam curativo até a cicatrização adequada da incisão e ausência de secreções na ferida operatória. Posteriormente, os cuidados habituais de assepsia a manipulação são requeridos ${ }^{26}$.

\section{Considerações finais}

Tendo em vista o achado nos dados da literatura, apresentamos o seguinte algoritmo (Figura 1) de acompanhamento dos pacientes com infecção de cateter de longa permanência.

Nele ressaltamos a importância de se caracterizar o tipo de infecção do cateter, visto que nos casos de infecção do óstio ou da loja/túnel o tratamento é bem estabelecido. O ponto mais controverso é a bacteremia relacionada ao cateter, cujo tratamento é dependente das condições do paciente e do microrganismo presente na cultura. Vale a pena frisar que, por se tratar de pacientes com múltiplas punções e com possível escassez de acesso venoso, a manutenção do cateter deve ser tentada, porém sem colocar em risco a saúde dos pacientes.

O tratamento agressivo e a vigilância desses pacientes se justificam, visto que a morbimortalidade causada por esse tipo de infecção é alta.

\section{Referencias}

1. Wolosker N, Carnevale FC. Acessos venosos centrais. In: Carnevale FC. Radiologia intervencionista e cirurgia vascular. São Paulo: Revinter; 2006. p. 328-34.

2. Liangos O, Gul A, Madias NE, Jaber BL. Long-therm management of the tunneled venous catheter. Semin Dial. 2006;19:158-64.
3. Caramori JT, Barretti P, Giannini M. Acessos vasculares para hemodiálise. In: Maffei FHA. Doenças vasculares periféricas. Rio de Janeiro: Medsi; 2002. p. 1724-36.

4. Marcondes CRR, Biojone CR, Cherri J, Moryia T, Piccinato CE. Complicações precoces e tardias em acesso venoso central. Análise de 66 implantes. Acta Cir Bras. 2000;15(suppl 2):32-8.

5. Aoki EE, Pizzolitto AC, Garcia LB, Pizzolitto EL. Staphylococcus aureus biofilms on central venous haemodialysis catheters. Braz J Microbiol. 2005;36:342-6.

6. Lentino JR, Baddour LM, Wray M, Wong ES, Yu VL. Staphylococcus aureus and other bacteremias in hemodialysis patients: antibiotic therapy and surgical removal of access site. Infection. 2000;28:355-60.

7. Groeger JS, Lucas AB, Thaler HT, et al. Infectious morbidity associated with long-term use of venous access devices in patients with cancer. Ann Intern Med. 1993;119:1168-74.

8. D'Angelo F, Ramacciato G, Caramitti A, et al. Totally implantable venous access systems. Analysis of complications. Minerva Chir. 1997;52:937-42.

9. Biffi R, de Braud F, Orsi F, et al. Totally implantable central venous access ports for long-term chemotherapy. A prospective study analyzing complications and costs of 333 devices with a minimum follow-up of 180 days. Ann Oncol. 1998;9:767-73.

10. Nishinari K, Wolosker N. Complicações Infecciosas do Cateter. In: Wolosker N, Kuzniec S. Acessos Vasculares para Quimioterapia e Hemodiálise. São Paulo: Atheneu; 2007. p. 73-8.

11. Mermel LA, Farr BM, Sherertz RJ, et al. Infectious Diseases Society of America; American College of Critical Care Medicine; Society for Healthcare Epidemiology of America. Guidelines for the management of intravascular catheter-related infections. Infect Control Hosp Epidemiol. 2001;22:222-42.

12. Vascular Access Society [site na internet]. Management of tunneled catheter infection. [citado 23/09/2008]. http://www.vascularaccesssociety.com/index.php?option $=$ com_content\&view=article $\&$ id $=38$.

13. Raad I, Hanna H, Maki D. Intravascular catheter-related infections: advances in diagnosis, prevention, and management. Lancet Infect Dis. 2007;7:645-57.

14. Maki DG. Pathogenesis, prevention and management of infections due to intravascular devices used for infusion therapy. In: Bisno AL, Waldvogel FA, editors. Infections associated with indwelling medical devices. Washington: American Society for Microbiology; 1989, p. 161-77.

15. Radd II, Sabbagh MF, Rand KH et al. Quantitative tip culture methods and diagnosis of central venous catheter-related infections. Diagn Microbiol Infect Dis. 1992;15:13-20.

16. Poole CV, Carlton D, Bimbo L, Allon M. Treatment of catheter-related bacteraemia with an antibiotic lock protocol: effect of bacterial pathogen. Nephrol Dial Transplant. 2004; 19:1237-44.

17. Maya ID, Carlton D, Estrada E, Allon M. Treatment of dialysis catheter-related Staphylococcus aureus bacteremia with an antibiotic lock: a quality improvement report. Am J Kidney Dis. 2007;50:289-95. 
18. Dugdale DC, Ramsey PG. Staphylococcus aureus bacteremia in patients with Hickman catheters. Am J Med. 1990;89:137-41.

19. Raad II, Sabbagh MF. Optimal duration of therapy for catheter-related Staphylococcus aureus bacteremia: a study of 55 cases and review. Clin Infect Dis. 1992;14:75-82.

20. Tuon FF, de Almeida GM, Costa SF. Central venous catheter-associated fungemia due to Rhodotorula spp.: a systematic review. Med Mycol. 2007;45:441-7.

21. Curvale-Fauchet N, Botterel F, Legrand P, Guillot J, Bretagne S. Frequency of intravascular catheter colonization by Malassezia spp. in adult patients. Mycoses. 2004;47:491-4.

22. Aschner JL, Punsalang A Jr, Maniscalco WM, Menegus MA. Percutaneous central venous catheter colonization with Malassezia furfur: incidence and clinical significance. Pediatrics. 1987;80:535-9.

23. Agarwal S, Thakur K, Kanga A, Singh G, Gupta P. Catheter-related candidemia caused by Candida lipolytica in a child with tubercular meningitis. Indian J Pathol Microbiol. 2008;51:298-300.

24. Angel-Moreno A, Boronat M, Bolaños M, Carrillo A, González S, Pérez Arellano JL. Candida glabrata fungemia cured by antibiotic-lock therapy: case report and short review. J Infect. 2005;51:e85-7.

25. Buckler BS, Sams RN, Goei VL, et al. Treatment of central venous catheter fungal infection using liposomal amphotericin-B lock therapy. Pediatr Infect Dis J. 2008;27:762-4.

26. Loterio MG. Esquema de manutenção de cateteres a longo prazo. In: Wolosker N, Kuzniec S. Acessos Vasculares para
Quimioterapia e Hemodiálise. São Paulo: Atheneu; 2007. p. 83-92.

Correspondência:

Milton Alves das Neves Junior

Serviço de Cirurgia Vascular, HSPM.

Rua Castro Alves, 60 - Aclimação

CEP 01532-400 - São Paulo

Tel: (11) 3208.2211, Ramal 223

E-mail: miltonanj@yahoo.com.br

Contribuições dos autores

Concepção e desenho do estudo: MAN Junior

Análise e interpretação dos dados: MAN Junior, RFC, AMOG Junior, TRP, AP, ER

Coleta de dados: MAN Junior, RFC, AMOG Junior, TRP

Redação do artigo: MAN Junior, RFC

Revisão crítica do texto: AP, ER

Aprovação final do artigo*: MAN Junior, RFC, AMOG

Junior, TRP, AP, ER

Análise estatística: N/A

Responsabilidade geral pelo estudo: MANJ, RFC, AMOG Junior, TRP, AP, ER

Informações sobre financiamento: MANJ

* Todos os autores leram e aprovaram a versão final submetida ao J Vasc Bras. 